\title{
Radiation Safety in Emergency Medicine: Balancing the Benefits and Risks
}

\author{
Raja Rizal Azman, FRCR, Mohammad Nazri Md Shah, MRad, Kwan Hoong Ng, PhD \\ All authors: Department of Biomedical Imaging, University Malaya Research Imaging Centre (UMRIC), Faculty of Medicine, University of Malaya, \\ Kuala Lumpur, Malaysia
}

The use of computed tomography (CT) in emergency departments has increased over several decades, as physicians increasingly depend on imaging for diagnoses. Patients and medical personnel are put at risk due to frequent exposure to and higher levels of radiation, with very little evidence of improvements in outcomes. Here, we explore why CT imaging has a tendency to be overused in emergency departments and the obstacles that medical personnel face in ensuring patient safety. The solution requires cooperation from all emergency care stakeholders as well as the continuous education of doctors on how CT scans help in particular cases.

Keywords: Ionizing radiation; Medical technology; Cumulative radiation dose; Decision-making process; Private practice

\section{INTRODUCTION}

The emergency department plays a vital role in the early diagnosis and treatment of patients, thrusting its personnel to the frontline of health care delivery under exigent circumstances $(1,2)$. Due to the nature of the emergency department, patient referrals have a high turnover rate, making the department fraught with hazard.

Clinicians and patients have high expectations from emergency department personnel to respond quickly and make accurate diagnoses. At the same time, doctors are expected to correctly filter out patients who do not require immediate attention.

This demanding environment, together with the many uncertainties, has caused emergency doctors to rely more heavily on advanced technology, and less on their clinical

Received July 2, 2018; accepted after revision 0ctober 9, 2018. Corresponding author: Raja Rizal Azman, FRCR, Department of Biomedical Imaging, University Malaya Research Imaging Centre (UMRIC), Faculty of Medicine, University of Malaya, Kuala Lumpur 50603, Malaysia.

- Tel: (603) 79492091 • Fax: (603) 79562253

- E-mail: rizalazman@ummc.edu.my

This is an Open Access article distributed under the terms of the Creative Commons Attribution Non-Commercial License (https://creativecommons.org/licenses/by-nc/4.0) which permits unrestricted non-commercial use, distribution, and reproduction in any medium, provided the original work is properly cited. skills, to minimize errors in clinical diagnoses. The request for "high-end" diagnostic imaging, particularly computed tomography (CT), has increased exponentially as clinicians demand accurate diagnostic tests and detailed images to visualize injuries and diseases before deciding on further management (3).

Although conventional radiography remains the tool of choice among emergency doctors, this article discusses the over-reliance on (or probable misuse of) CT scans, leading to radiation overexposure for patients and doctors themselves $(4,5)$. This scenario is alarming, particularly when emergency doctors lower their safeguard due to pressure from patients and their referring colleagues, who may lack insight on the principles of radiation exposure.

Despite the danger of radiation exposure, the use of CT has been shown to significantly improve diagnoses and outcomes in trauma cases (6). It displays high accuracy in the assessment of non-traumatic acute abdominal pain (7) and may predict patient outcomes in acute stroke $(8,9)$.

The benefits of using CT must, however, be weighed against the potential harm of the increasing exposure to ionizing radiation, which is the main safety concern when working in an emergency department (4). Unfortunately, distractions, such as staff and patient security, chemicals and biohazards, and overcrowding have relegated radiation exposure to a lower priority. The presence of numerous 
Take Home Points

1. Recognizing that radiation protection in emergency departments presents unique scenario

2. Vital to implement appropriateness criteria in performing CT scans

3. Enhancing knowledge on risks of ionizing radiation can reduce requests for unnecessary scans

4. Promoting public awareness can improve communication and understanding among clinicians and patients

5. Performing routine clinical audits will ensure adherence of appropriateness criteria and guidelines

$\mathrm{CT}=$ computed tomography

clinical and non-clinical teams in the department further complicates the issue as it becomes less clear which party bears the responsibility for radiation safety.

In this article, we aim to highlight trends in the use of CT in emergency departments and the knowledge gap between different stakeholders. We also highlight some solutions for performing CT scans in a safe and effective manner (Table 1).

\section{CT Use Has Increased Rapidly}

In a recent report about the abuse of medical technology, 2 of the 10 issues involved ionizing radiation exposure from CT scans in hospital emergency departments. The report cited the inappropriate use of CT in investigating pulmonary emboli and respiratory tract infections (10). In addition to the potential harm from radiation exposure and contrast media toxicity, the study mentioned unnecessary delays, increased costs, and overdiagnosis of incidental findings as a result of inappropriate usage.

Between 1995 and 2007, the United States experienced an exponential increase in CT use for emergency cases, growing from $2.8 \%$ to $13.9 \%$ of all patient visits. The cumulative radiation dose administered from CT has also increased by approximately 23 -fold compared with a 10-fold increase in patient volume for the same time period (3).

of particular concern is a subset of patients presenting at emergency departments who are exposed to multiple CT examinations. A study in 2009 showed that this population received a mean effective dose of $122 \mathrm{mSv}$ and a maximum of $579 \mathrm{mSv}$ over a 7-year period, corresponding to an increased lifetime cancer risk of one in 82 and one in 17, respectively (11). A separate study showed that the use of CT scans has increased in emergency departments compared with the hospitals' in-patient and outpatient units, or at private clinics (12). This increase is thought to be due to a combination of more scans being performed for common indications, like headaches, trauma, and seizure, as well as its expanded usage for new indications, such as back and chest pains.
A recent study observed that CT scan requests for evaluating headaches have increased from $17.5 \%$ in 1996 to $33.3 \%$ in 2014 . For urinary tract infections, the figure went up from 0 in 1996 to $48 \%$ of presentations in 2016 (13). A Taiwanese study found that although the use of CT had increased in emergency departments, the hospital admission of patients who underwent scans had decreased (14), indicating that the use of CT has largely been for non-emergency conditions and to "rule-out" a particular diagnosis.

A recent review has identified three factors that predisposes the overuse of radiological imaging in emergency departments-poor integration of services, overcrowding or reduced staffing levels, and a litigious environment that encourages the practice of defensive medicine (15).

\section{The Knowledge Gap Must Be Closed}

Emergency personnel who request diagnostic imaging have demonstrated a knowledge gap in the risks of radiation exposure. This knowledge deficiency is particularly pronounced among nurses and physician assistants. A study in 2016 showed that $44.6 \%$ of health care providers surveyed were unable to identify which of six common imaging modalities used radiation. Nurse practitioners and physician assistants were more likely to incorrectly identify radiography and fluoroscopy as modalities that did not use ionizing radiation (16). A separate study showed that radiology residents also had similar knowledge gaps with only $7 \%$ able to state the radiation dose of a chest X-ray and $16 \%$ able to identify the dose of a CT scan of the abdomen and thorax (17).

A 2004 study revealed that only $9 \%$ of emergency physicians believed that $\mathrm{CT}$ scans posed an increased risk of cancer, while many others could not relate the radiation dose of a CT scan to that of a chest radiograph as a reference point (18). Compounding this issue, a 2010 study demonstrated that only $34 \%$ of patients believed that 
Table 2. Typical Radiation Effective Dose for Common SinglePhase CT Procedures in Emergency Department

\begin{tabular}{lcc}
\hline \multicolumn{1}{c}{ Examination } & $\begin{array}{r}\text { Effective } \\
\text { Dose }(\mathrm{mSv})\end{array}$ & $\begin{array}{c}\text { Chest Radiograph Effective } \\
\text { Dose }(0.02 \mathrm{mSv})\end{array}$ \\
\hline CT brain & 2.8 & 140 \\
CT chest & 6.2 & 310 \\
CT abdomen and pelvis & 17.2 & 860 \\
CT whole aorta & 13.4 & 670 \\
CT pulmonary vessels & 3.6 & 180 \\
CT cervical spine & 2.1 & 105 \\
CT lumbar spine & 2.7 & 135 \\
\hline
\end{tabular}

Adapted from Brix et al. Eur Radiol 2003;13:1979, with permission of Springer (29)

the radiation dose of a CT scan was higher than a chest radiograph, while $74 \%$ of patients agreed that having a diagnosis from a CT scan was more important than concerns about radiation exposure (19). The effective radiation doses for common CT examinations in the emergency department are summarized in Table 2.

When clinicians were made aware of the risks from highdosage $\mathrm{CT}$ radiation, there was a significant $(>50 \%$ ) reduction in scan requests (20). Radiologists should be taking the lead in educating their fellow residents, nurses, and patients to help close the knowledge gap.

\section{Proceed with Caution and Solid Reason}

To justify the use of a CT scan involves weighing the benefits against the detrimental effects on patients. This process involves obtaining clinical information, understanding the evidence for investigating the suspected pathology, and awareness of the side effects of ionizing radiation for the chosen modality.

It can be very difficult to comply with this process. Patients frequently fail to provide their full medical history due to time constraints during the consultation and a lack of understanding of the severity of their illness. Furthermore, emergency physicians also frequently do not have access to medical or radiographic records due to poor record-keeping by the hospital, or the patients are new and have never been under their care.

Reduced access to emergency specialists and radiologists, particularly during out-of-hours care, also widens the knowledge gap and compounds clinical uncertainty. Emergency physicians are expected to make clinical decisions with limited information, hence, encouraging the physicians to err on the side of safety and request CT scans to exclude pathology, even for low-risk cases.

The use of evidence-based, clinical decision support algorithms can potentially play an important role in improving the decision-making process. A study on the use of such algorithms for pulmonary embolism, which were incorporated into the requesting mechanism of a hospital emergency department, showed a reduction of $20.1 \%$ in the number of CT pulmonary angiograms requested and a $69 \%$ increase in the diagnostic yield of pulmonary emboli (21). When used for mild traumatic brain injuries, a study found a reduction of $13.4 \%$ with no increase in delayed diagnosis of radiologically significant findings (22).

Frontline health care providers often have limited knowledge of the carcinogenic effects of ionizing radiation and lack the skills to communicate this risk adequately (23). As the modalities involved become increasingly complex, and the evidence base for investigating conditions continues to evolve, clinicians will come to rely on radiologists to justify a scan, and inform other colleagues on the current evidence and risks of investigation.

Protocols for using CT scans have been developed by various medical organizations. For example, the American College of Radiology (ACR) has had its own appropriateness criteria since 1993 and is continuously revising it to stay relevant. Its guidelines aim to help referring physicians and other health care providers in deciding the best imaging modality for a given clinical condition. Some common indications encountered in the emergency department and the corresponding appropriateness of either a CT scan of the abdomen and pelvis or brain are summarized in Tables 3 and 4 .

A survey in 2009 found that only $2.4 \%$ of physicians actually used the ACR's appropriateness criteria as one of their top three references. Radiologist consultation was found to be the most cited source of referral information, with $64.3 \%$ of respondents placing it in their top three sources (24). This highlights the important role that radiologists play in disseminating evidence, despite the formulation of guidelines by an organization that has the most expertise on the matter.

Radiologists need to equip themselves and their trainees with the knowledge and communication skills to guide referring clinicians. An obstacle in implementing the ACR's appropriateness criteria may be resistance from referring clinicians themselves. This must be resolved through discussions so a consensus can be reached on which criteria to implement, and periodical audits must be performed to ensure that these criteria are adhered to. As the association 
Table 3. ACR Appropriateness Criteria for Contrast-Enhanced CT Abdomen and Pelvis*: Common Indications in Casualty

\begin{tabular}{|c|c|c|c|}
\hline \multirow{2}{*}{ Indication } & \multicolumn{3}{|c|}{ Appropriateness } \\
\hline & Usually Appropriate & May Be Appropriate & Usually Not Appropriate \\
\hline Acute non-localised abdominal pain and fever & $\sqrt{ }$ & & \\
\hline Blunt abdominal trauma, stable patient & $\sqrt{ }$ & & \\
\hline Left lower quadrant pain-suspected diverticulitis & $\sqrt{ }$ & & \\
\hline Suspected appendicitis & $\sqrt{ }$ & & \\
\hline Suspected small bowel obstruction & $\sqrt{ }$ & & \\
\hline Acute pyelonephritis in complicated patient ${ }^{\dagger}$ & $\sqrt{ }$ & & \\
\hline Suspected abdominal aortic aneurysm & $\sqrt{ }$ & & \\
\hline Acute pancreatitis & & $\sqrt{ }$ & \\
\hline Suspected acute mesenteric ischaemia & & $\sqrt{ }$ & \\
\hline Upper gastrointestinal bleed (non-variceal) & & $\sqrt{ }$ & \\
\hline Right upper quadrant pain & & $\sqrt{ }$ & \\
\hline Haematuria & & $\sqrt{ }$ & \\
\hline Suspected lower urinary tract trauma & & $\sqrt{ }$ & \\
\hline Blunt abdominal trauma, unstable patient & & & $\sqrt{ }$ \\
\hline Acute pyelonephritis in uncomplicated patient & & & $\sqrt{ }$ \\
\hline Suspected urolithiasis & & & $\sqrt{ }$ \\
\hline
\end{tabular}

* Contrast-enhanced CT abdomen and pelvis does not include plain (non-contrast-enhanced) CT abdomen and pelvis, CTA, or multiphase $\mathrm{CT}$ abdomen and pelvis, ${ }^{\dagger}$ Diabetes or immunocompromised or history of stones or prior renal surgery or not responding to therapy. ACR $=$ American College of Radiology, CTA = computed tomography angiography

Table 4. ACR Appropriateness Criteria for Plain (Non-Contrast-Enhanced) CT Head*: Common Indications in Casualty

\begin{tabular}{|c|c|c|c|}
\hline \multirow{2}{*}{ Indication } & \multicolumn{3}{|c|}{ Appropriateness } \\
\hline & Usually Appropriate & May Be Appropriate & Usually Not Appropriate \\
\hline Suspected stroke & $\sqrt{ }$ & & \\
\hline Suspected acute subarachnoid bleed & $\sqrt{ }$ & & \\
\hline Clinically suspected parenchymal bleed & $\sqrt{ }$ & & \\
\hline Suspected dural venous sinus thrombosis & $\sqrt{ }$ & & \\
\hline Acute focal neurological deficit & $\sqrt{ }$ & & \\
\hline Sudden onset of severe headache & $\sqrt{ }$ & & \\
\hline $\begin{array}{l}\text { Head trauma-minor, closed injury (GCS > 12). Imaging indicated } \\
\text { by NOC or CCHR or NEXUS-II clinical criteria }\end{array}$ & $\sqrt{ }$ & & \\
\hline Head trauma. Moderate or severe closed injury $(\mathrm{GCS}<13)$ & $\sqrt{ }$ & & \\
\hline Traumatic visual defect & $\sqrt{ }$ & & \\
\hline New-onset seizure, unrelated to trauma & $\sqrt{ }$ & & \\
\hline $\begin{array}{l}\text { Head trauma-minor, closed injury (GCS }>12) \text {. Imaging not } \\
\text { indicated by NOC or CCHR or NEXUS-II clinical criteria }\end{array}$ & & & $\sqrt{ }$ \\
\hline
\end{tabular}

*Plain (non-contrast-enhanced) CT head does not include contrast-enhanced CT head, CTA, or multiphase CT head. CCHR = Canadian CT Head Rules, GCS = Glasgow Coma Scale, NEXUS-II = National Emergency X-radiography Utilisation Study criteria, NOC $=$ New Orleans Criteria

between patients, clinicians, and modality, radiologists play an important role in monitoring and optimizing the radiation dose in $\mathrm{CT}$. Dose-saving strategies are constantly evolving. Radiologists should lead teams of physicists and technologists to ensure the most up to date strategies are employed (25).

Other factors that encourage the misuse of CT scans is poor knowledge and apathy for patients. Some patients have unrealistically high expectations for health care services and demand expensive investigations, like CT scans, without knowing the limitations and disadvantages.

In private practice, there is a monetary drive among clinicians and health care institutions to perform CT scans, whether indicated or not. Patients who are accustomed to treatment in private hospitals have been observed to insist for the same treatment when they are treated in public hospitals. 


\section{Policies Should Reflect Local Needs}

The solution to overcoming CT overuse in the emergency department may require input from policymakers, both at national and local levels. Public need, funding, and cost of health care may vary greatly between countries. Therefore, this must be accounted for when creating policies and guidelines for the safe, equitable, and efficient use of CT. Guidelines applied in Europe may not be useful in Southeast Asian countries like the Philippines, for example, and vice versa.

An example of this difference based on geographic location is the difference in recommendations between the ACR appropriateness criteria and the National Institute of Health and Care Excellence (NICE) guidelines in the United Kingdom (UK) for the evaluation of head injuries. Both guidelines agree on the need for a head CT evaluation for patients that meet certain criteria. However, the NICE guidelines risk stratify patients further into those requiring a scan within 1 hour and those that can be delayed to 8 hours. This difference likely stems from the difference in on call availability and pressures on health care providers particularly during out-of-hours care in the publicly-funded National Health Service in the UK.

\section{The Way Forward}

There is a need for judicious use of $\mathrm{CT}$, not solely in emergency departments, but in the health care industry as a whole. Following a meeting in 2008 , the International Atomic Energy Agency published an article advocating the use of justifying and delineating steps to improve CT use (26). To make it easy to remember, the authors summarized the measures in the form of 3As-awareness, appropriateness, and audit.

Awareness involves educating health care professionals and the public on the importance of justification in order to reduce radiation exposure. This requires a common framework for communication, not only with regard to the risks, but also to discuss the relevant ethical, clinical, and legal issues. The use of guidelines and appropriateness criteria has been shown to reduce the number of unnecessary scans and improve the quality of radiological requests (27). Educational reminders detailing appropriateness of the investigation requested attached to radiology reports was shown to have a sustained effect in reducing the number of inappropriate requests (28).
Clinical audit ensures that the goals of justification are met and that the process is continuously improved. This will encourage ownership of the system and help promote change.

The process of delivering efficient, safe, and effective CT scans in the emergency department requires the continuous engagement of all stakeholders. Careful discussions with health care professionals, patient groups, administrators, and insurers are required to ensure that the concerns of all groups are addressed. The stakeholders must understand their own roles and challenges, as well as those faced by others. Failure to engage each other continuously will result in a transient change, with no sustainable benefits.

\section{Conflicts of Interest}

The authors have no potential conflicts of interest to disclose.

\section{ORCID iD}

\section{Raja Rizal Azman https://orcid.org/0000-0001-8153-7798}

\section{REFERENCES}

1. Liebeskind DS, Jahan R, Nogueira RG, Jovin TG, Lutsep $\mathrm{HL}$, Saver JL. Early arrival at the emergency department is associated with better collaterals, smaller established infarcts and better clinical outcomes with endovascular stroke therapy: SWIFT study. J Neurointerv Surg 2016;8:553-558

2. Cullen $L$, Greenslade JH, Menzies L, Leong A, Than M, Pemberton $C$, et al. Time to presentation and 12-month health outcomes in patients presenting to the emergency department with symptoms of possible acute coronary syndrome. Emerg Med J 2016;33:390-395

3. Larson DB, Johnson LW, Schnell BM, Salisbury SR, Forman HP. National trends in CT use in the emergency department: 19952007. Radiology 2011;258:164-173

4. Fazel R, Krumholz HM, Wang Y, Ross JS, Chen J, Ting HH, et al. Exposure to low-dose ionizing radiation from medical imaging procedures. N Engl J Med 2009;361:849-857

5. Raja AS, Ip IK, Sodickson AD, Walls RM, Seltzer SE, Kosowsky $J M$, et al. Radiology utilization in the emergency department: trends of the past 2 decades. AJR Am J Roentgenol 2014;203:355-360

6. Huber-Wagner S, Lefering R, Qvick LM, Körner M, Kay MV, Pfeifer KJ, et al.; Working Group on Polytrauma of the German Trauma Society. Effect of whole-body CT during trauma resuscitation on survival: a retrospective, multicentre study. Lancet 2009;373:1455-1461

7. Millet I, Sebbane M, Molinari N, Pages-Bouic E, Curros-Doyon F, 
Riou B, et al. Systematic unenhanced CT for acute abdominal symptoms in the elderly patients improves both emergency department diagnosis and prompt clinical management. Eur Radiol 2017;27:868-877

8. Barber PA, Demchuk AM, Zhang J, Buchan AM. Validity and reliability of a quantitative computed tomography score in predicting outcome of hyperacute stroke before thrombolytic therapy. ASPECTS Study Group. Alberta Stroke Programme Early CT Score. Lancet 2000;355:1670-1674

9. Wildermuth S, Knauth M, Brandt T, Winter R, Sartor K, Hacke W. Role of CT angiography in patient selection for thrombolytic therapy in acute hemispheric stroke. Stroke 1998;29:935-938

10. Morgan DJ, Dhruva SS, Coon ER, Wright SM, Korenstein D. 2017 update on medical overuse: a systematic review. JAMA Intern Med 2018;178:110-115

11. Griffey RT, Sodickson A. Cumulative radiation exposure and cancer risk estimates in emergency department patients undergoing repeat or multiple CT. AJR Am J Roentgenol 2009;192:887-892

12. Levin DC, Rao VM, Parker L, Frangos AJ, Sunshine JH. Recent shifts in place of service for noninvasive diagnostic imaging: have hospitals missed an opportunity? J Am Coll Radiol 2009;6:96-99

13. Rosenkrantz AB, Hanna TN, Babb JS, Duszak R Jr. Changes in emergency department imaging: perspectives from national patient surveys over two decades. J Am Coll Radiol 2017;14:1282-1290

14. Hu SY, Hsieh MS, Lin MY, Hsu CY, Lin TC, How CK, et al. Trends of CT utilisation in an emergency department in Taiwan: a 5-year retrospective study. BMJ Open 2016;6:e010973

15. Tung M, Sharma R, Hinson JS, Nothelle S, Pannikottu J, Segal JB. Factors associated with imaging overuse in the emergency department: a systematic review. Am J Emerg Med 2018;36:301-309

16. Ditkofsky N, Shekhani HN, Cloutier M, Chen ZN, Zhang C, Hanna TN. Ionizing radiation knowledge among emergency department providers. J Am Coll Radiol 2016;13:1044-1049.e1

17. Divrik Gökçe S, Gökçe E, Coşkun M. Radiology residents' awareness about ionizing radiation doses in imaging studies and their cancer risk during radiological examinations. Korean J Radiol 2012;13:202-209

18. Lee CI, Haims AH, Monico EP, Brink JA, Forman HP. Diagnostic CT scans: assessment of patient, physician, and radiologist awareness of radiation dose and possible risks. Radiology 2004;231:393-398

19. Takakuwa KM, Estepa AT, Shofer FS. Knowledge and attitudes of emergency department patients regarding radiation risk of CT: effects of age, sex, race, education, insurance, body mass index, pain, and seriousness of illness. AJR Am J Roentgenol 2010;195:1151-1158

20. Gimbel RW, Fontelo P, Stephens MB, Olsen CH, Bunt C, Ledford $\mathrm{CJ}$, et al. Radiation exposure and cost influence physician medical image decision making: a randomized controlled trial. Med Care 2013;51:628-632

21. Raja AS, Ip IK, Prevedello LM, Sodickson AD, Farkas C, Zane $\mathrm{RD}$, et al. Effect of computerized clinical decision support on the use and yield of CT pulmonary angiography in the emergency department. Radiology 2012;262:468-474

22. Ip IK, Raja AS, Gupta A, Andruchow J, Sodickson A, Khorasani R. Impact of clinical decision support on head computed tomography use in patients with mild traumatic brain injury in the ED. Am J Emerg Med 2015;33:320-325

23. Lam DL, Larson DB, Eisenberg JD, Forman HP, Lee CI. Communicating potential radiation-induced cancer risks from medical imaging directly to patients. AJR Am J Roentgenol 2015;205:962-970

24. Bautista AB, Burgos A, Nickel BJ, Yoon JJ, Tilara AA, Amorosa JK. Do clinicians use the American College of Radiology appropriateness criteria in the management of their patients? AJR Am J Roentgenol 2009;192:1581-1585

25. Goo HW. CT radiation dose optimization and estimation: an update for radiologists. Korean J Radiol 2012;13:1-11

26. Malone J, Guleria R, Craven C, Horton P, Järvinen H, Mayo $J$, et al. Justification of diagnostic medical exposures: some practical issues. Report of an International Atomic Energy Agency Consultation. Br J Radiol 2012;85:523-538

27. Moskowitz H, Sunshine J, Grossman D, Adams L, Gelinas L. The effect of imaging guidelines on the number and quality of outpatient radiographic examinations. AJR Am J Roentgenol 2000;175:9-15

28. Ramsay CR, Eccles M, Grimshaw JM, Steen N. Assessing the long-term effect of educational reminder messages on primary care radiology referrals. Clin Radiol 2003;58:319-321

29. Brix G, Nagel HD, Stamm G, Veit R, Lechel U, Griebel J, et al. Radiation exposure in multi-slice versus single-slice spiral CT: results of a nationwide survey. Eur Radiol 2003;13:1979-1991 